\title{
INEQUALITIES RELATED TO ISOTONICITY OF PROJECTION AND ANTIPROJECTION OPERATORS
}

\author{
GEORGE ISAC AND LARS-ERIK PERSSON
}

\begin{abstract}
A sharp inequality named "the property of four elements" has recently been proved and studied in [6] and [12]. One particular reason for this is that the inequality is closely related to the isotonicity of the projection operator onto a closed convex set in an ordered Hilbert space.

In this paper we prove and study a dual reversed sharp inequality. Moreover, we introduce the concept of antiprojection operator onto a compact non-empty set of a Hilbert space and prove that our new inequality is closely related to the isotonicity of such an operator. Moreover, we prove that both of these inequalities hold also in the reversed direction but of course with other constants.
\end{abstract}

Mathematics subject classification (1991): Primary: 26D20, 47B99; Secondary: 26D15, 46E15, 46E20, 47A99.

Key words and phrases: Inequalities, Banach spaces, Hilbert spaces, modular spaces, projection operators, antiprojection operators, isotone operators, isotone additive functionals, Lyapunov functionals.

\section{REFERENCES}

[1] BAUSCHKE H. H. AND BORWEIN J. M., On projection algorithms for solving convex feasibility problems, SIAM Review 38, 3 (1996), 367-426.

[2] Bernau S. J., Isotone projection cones, (Preprint), Depth. Math. Sciences, Univ. of Texas at El Paso, 1993.

[3] DeUTSCH FR., The method of alternating orthogonal projections, Approximation Theory, Spline Functions and Applications (Ed. S. P. Singh), Kluwer Academic Publishers, NATO, ASI Series (1992), $105-121$.

[4] DyKstRa R. L., An algorithm for restricted least square regression, J. Amer. Statistical Assoc. 78 Nr. 384 (1983), 837-842.

[5] Clarkson J. A., Uniformly convex spaces, Trans. Amer. Math. Soc. 40 (1936), 396-414.

[6] IsAC G., On the order monotonicity of the metric projection operator, Approximation Theory, Wavelets and Applications (Ed.. S. P. Singh), Kluwer Academic Publishers NATO, ASI Series (1995), 365-379.

[7] ISAC G. AND NÉMETH A. B., Monotonicity of metric projections onto positive cones in order Euclidean spaces, Ark. Math. 46 (1986), 568-576 (and Corrigendum).

[8] Every generating isotone projection cone is latticial and correct, J. Math. Anal. Appl. 147 (1990), 56-62.

[9] Isotone projection cones in Hilbert spaces and the complementarity problem, Boll. Un. Math. Ital. 7 (1990), 773-802.

[10] Projection methods, isotone projection cones and the complementarity problem, J. Math. Anal. Appl. 153 (1990), 258-275.

[11] Isotone projection cones in Euclidean spaces, Ann. Sci. Math. Québec 16 (1992), 35-52.

[12] ISAC. G. AND PERSSON L. E., On an inequality related to the isotonicity of the projection operator, J. Approx. Theory 86 Nr. 2 (1996), 129-143.

[13] ISAC. G. AND LEWICKI. G., On the property of four element, Preprint (1997).

[14] PHELPS R. R., Metric projection and the gradient projection method in Banach spaces, SIAM J. Control Optim. 23 (1985), 973-977. 


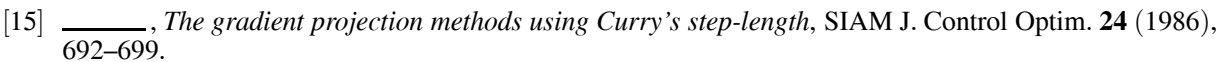

[16] RoBINSON S. M., Nonsingularity and symmetry for linear normal maps, Math. Programming 62 (1992), $415-425$.

[17] _ Normal maps induced by linear transformation, Math. Oper. Research 17 Nr. 3 (1992), 691-714.

[18] SOLODOV M. V. AND P. TSENG, Modified projection-type methods for monotone variational inequalities, SIAM J. Control Optim. 34 Nr. 5 (1996), 1814-1830.

[19] Zarantonello E. H., Projections on convex sets in Hilbert spaces and spectral theory, Contributions to Nonlinear Functional Analysis (Ed. E. H. Zarantonello), Acad. Press, New York, 1971, pp. 237-424. 